\title{
Interactions in virtual learning environments: new roles for digital technology
}

\author{
Marcelo C. Borba ${ }^{1}$ - Aparecida Santana de Souza Chiari ${ }^{2}$ • \\ Helber Rangel Formiga Leite de Almeida ${ }^{3}$ (D)
}

Published online: 13 April 2018

(C) Springer Science+Business Media B.V., part of Springer Nature 2018

\begin{abstract}
For the last 10 years, online pre-service teacher distance education has increased significantly in Brazil. As a result, research on this educational modality has also increased, in particular, research investigating the different roles students and teachers play in these courses. The purpose of this paper is to analyze the role of digital technologies in two specific contexts: how teachers, tutors, and students play a role in producing interactive digital didactic material and how digital technologies themselves can play a role in teaching distance learning courses. But for these roles to emerge, we point to the need for participants of online courses to interact collaboratively. To identify these roles, grounded theory, a branch of qualitative research, was used as the two roles were articulated. Data were produced from virtual observations in virtual learning environments and virtual interviews. The results stress that both highlighted roles are related. They transform teacher and student roles and participation in the virtual classroom, and an "agency of media" emerges in online mathematics education.
\end{abstract}

Keywords Distance online education IDDM $\cdot$ Poly-teaching media $\cdot$ Grounded theory

Marcelo C. Borba

mborba@rc.unesp.br

Aparecida Santana de Souza Chiari

cidach@gmail.com

Helber Rangel Formiga Leite de Almeida

helber.rangel@gmail.com

1 Departamento de Educação Matemática, Universidade Estadual Paulista (UNESP), Avenida 24A, 1515, Bela Vista, Rio Claro, São Paulo 13506-900, Brazil

2 Instituto de Matemática (INMA), Universidade Federal de Mato Grosso do Sul (UFMS), Cidade Universitária, s/n, Campo Grande, Mato Grosso do Sul 79090-900, Brazil

3 Unidade Acadêmica de Ciências e Tecnologia Ambiental, Universidade Federal de Campina Grande (UFCG-POMBAL), Rua Jario Vieira Feitosa, Pombal, Paraíba 58840-000, Brazil 


\section{Introduction}

Technologies have changed humankind.

Man moves culturally, affected by contemporary technologies. They change man's ways of thinking, feeling, and acting. They also change man's ways of communicating and acquiring knowledge. (Kenski, 2008, p. 21)

As a result of technological advances, societies have also changed. In particular, educational processes are being transformed (Almeida, 2015), although not at the same pace: "Despite the massive investment on resources, both financial and human, in pursuit of this aim, impact on the reality of school practices is limited" (Lagrange \& Kynigos, 2014, p. 381). In the last 4 years, Borba et al. (2016) have mapped the development of research on the interface between digital technology and mathematics education. Five trends were found by the international team that proposed this report to the International Congress on Mathematical Education (ICME)-13; among them were new facets of blended learning. This paper studies classrooms of online courses, in which blended learning is practiced. Most instruction was done online, but assessments were generally conducted face-to-face.

Independent of research, digital technologies have "invaded" the classroom in the past few years, as students have incorporated the Internet into it, whether as a part of a pedagogical proposal or not (Borba, 2009). Additionally, digital technology has already made history in mathematics education over the last 30 years or so. Borba (2012) identifies four phases of digital technologies prevalent in online mathematics education, where one phase does not imply the end of another, but rather characterizes new branches of practice in research and/or in the classroom. According to him, the first phase is characterized by the use of LOGO and the notion of programming, the second phase by the popularization of personal computers and the use of specific topic software such as Cabri or Geometer's Sketchpad, and the third one by the dissemination of Internet use and online courses. The fourth phase, mainly characterized by quick Internet access, expanded the possibilities in the classroom and, among other changes, made online education even more popular.

Borba, Gracias, and Chiari (2015, p. 844) indicate that distance education is gaining strength in recent decades and is presented as an educational modality that seeks the democratization of educational opportunities, as well as a way to address the problem of teaching that is concentrated in large urban centers. But online education and distance education are not synonymous. In Brazil, distance education has seen three generations. The first, in the early 1900s, was based on technical training and marked by correspondence education. The second generation, in the 1970s and 1980s, had its strength in offering supplementary courses via satellite TV, with students receiving printed material to follow the lessons. The third generation, begun in the mid-1990s and continuing through today, is marked specifically by offering higher education courses (Zabel \& Almeida, 2015). Since 2000, online courses in mathematics education for teachers have been offered continually in this country, making it one of the pioneers of this modality in education.

Expanding the scope for research beyond the Brazilian borders, we find works that focus on several aspects of online mathematics teacher education, specifically about interaction and digital technologies, our major themes here. Goos and Geiger (2012), for example, present theoretical issues underpinning the use and design of online learning environments in mathematics teacher education. These authors consider the contribution of social theories of learning and use them to conceptualize technology-mediated interaction. 
Interaction is also analyzed by Gueudet, Sacristán, Soury-Lavergne, and Trouche (2012) and Kynigos and Kalogeria (2012). In the first article, the authors argue from the viewpoint of professional development. They study resources that online teacher educators need and how such resources change, due to the educators' specific wants and skills, among other things. In the second article, they analyze how newly trained teacher educators interact with their designs and productions, in the context of in-service courses they presented to colleagues.

Clay, Silverman, and Fischer (2012) interpret the contribution of collaboration, a notion related to interaction, to support teachers' development of mathematical knowledge for teaching (MKT) algebra in a collaborative problem-solving activity.

Thus, it is clear that interaction is a central element to online teacher education as well as to the use of digital technologies, since the physical distance implies the search for technological tools of communication. However, in addition to communication, we are also interested in analyzing how digital technologies can participate in the teaching process in a more intense way.

Borba and Llinares (2012) argue that pre-service teacher online distance education courses are an emerging scientific field. According to the authors, there has been increasing interest in investigating the role that new communication interfaces are assuming in the professional development of teachers. In particular, the foci of this research have included the following:

(1) Identifying and analyzing both the affordances of this new educational environment and the challenges teachers and students encounter when learning and teaching without faceto-face interaction;

(2) The ways in which the nature of the interactional environment (the interface between participants) affects both the characteristics of the interaction and the potential that the interaction holds for knowledge building (from human-computer interactions and human-human interactions), and

(3) The relationship between online interaction and learning (Borba \& Llinares, 2012, p. 697-698).

For many years, in this country that pioneered this modality of education, distance education was considered to be second-class education, a form of mass education. Various initiatives, however, have shown that there are modifications that promote interaction and dialogue between teachers and students, as well as among the students themselves (Engelbrecht \& Harding, 2005).

It is important to clarify that, apart from the focus on advantages and disadvantages that has dominated the scientific debate about this modality for more than a decade, the objective of this article is to research distance education that is actually responsible for a significant part of teacher education in Brazil. In order to do this, we have used grounded theory, a research method that values context and allows creation of theorizations from the data.

To start, however, we must contextualize what we understand by the term "distance education." We are supported by Maltempi and Malheiros (2010) as we assume that distance education can be considered an educational modality that occurs partially or entirely in different moments and/or spaces where communication between those involved is accomplished through television, mailings, the Internet, and so on. In the specific case of Internet utilization, the term "online" can be added to the name, thus differentiating it from other forms of communication. Specifically, online distance education can be understood as a type of education that takes place via the Internet and associated technologies. 
The background of this research centers on several mathematics teacher education courses offered by the Brazilian Open University (UAB), an institution that has impacted the increase of this educational modality in Brazil. Since UAB's creation, facets of its courses have been researched. Studies have focused, for instance, on how mathematics communication occurs between participants, as well as how the use of digital technologies impacts courses. In particular, we focused on how digital technologies act in the production of mathematical knowledge.

Virtual learning environments ${ }^{1}$ (VLE) have been developed as a locus to make online teacher education possible. We propose, however, that there are specific ways in which this technology can have agency and can be active in online mathematics education. More specifically, we show below how the interactions among students, tutors, and teachers in VLEs provide for the construction of interactive digital didactic material (IDDM) and how digital technologies themselves can play a role in teaching distance learning courses. We show examples of how digital technology is being transformed by collectives that include students, teachers, and these technologies. First, however, we present our vision of knowledge and the methodology used in the research.

\section{Humans-with-media}

Knowledge is a difficult concept not only to define, but also to understand in how it is acquired, constructed, and produced. Philosophical debates on this matter are never-ending. However, we present our perspective: knowledge is produced by humans as well as by different media, such as writing, or by the multimodal text produced by computer technologies. Borba and Villarreal (2005) anchored this notion on two other ideas, coming respectively from activity theory and from the philosophy of technics: (a) the reorganization of thinking notion (Tikhomirov, 1981), stating that computers can be seen as an actor who rearranges human activity, and (b) collective intelligence (Lévy, 1993), a way in which humans think and share their knowledge using certain technology (oral, written, or computer simulations). Thus, these authors intertwined both "theoretical perspectives," since the two complement one another and are influenced by each other; then, the authors developed a theoretical construct called humans-with-media. They emphasized that

[...] humans-with-media, human-media or humans-with-technologies are metaphors that can lead to insights regarding how the production of knowledge itself takes place [...] this metaphor synthesizes a view of cognition and of the history of technology that makes it possible to analyze the participation of new information technology 'actors' in these thinking collectives in a way that we do not judge whether there is 'improvement' or not, but rather identify transformations in practice. (Borba \& Villarreal, 2005, p. 23)

These authors pointed out the interaction between "different worlds" that happens through a dialogic relationship between a user of a given technology and the ones who designed that given piece of software. They also emphasized that information and communication technologies (ICT) differ qualitatively from oral and written media by changing the linearity of reasoning. Jacinto and Carreira (2017) understand that students tend to unify their mathematical and technological knowledge as a result of the creation of a collective of humanswith-media.

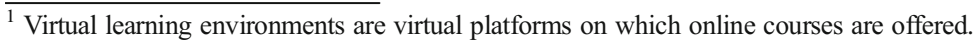


Similarly, other theoretical perspectives also propose that there is an intershaping relationship between humans and media, as proposed, originally in 1993, by Borba (2012). Rabardel and Waern (2003) theorize about an artifact's transformation into an instrument from a user's appropriation, even though it is not clear whether they accept that digital technology itself also shapes humans. Hoyles and Noss (2003) also analyze this relationship from a theoretical point of view and argue that "learning is highly sensitive to small changes in technologies, and that the design of tools and learning tended to co-evolve" (p. 339). This is because, among other factors, several studies point out that the tools shape learning, but often do so in an unforeseen way.

The theoretical perspective of humans-with-media used in this work emphasizes and highlights the role of the media but with no intention of quantifying the importance of the unity formed between humans and media. For the authors, this collective should be considered as the minimum unit of analysis, so that there is no production of human knowledge without the influence of media, nor the development of media without the influence of humans.

Looking at mathematics production in online environments, some authors, such as Bairral (2005) and Silva (2000), understand that this production occurs differently from that occurring in the face-to-face classroom, mainly due to the capability of technology present in these environments, like the chat tool, for example:

[...] one of the aspects that differentiates online mathematics production in the face-toface classroom is related to changes in forms of expression of mathematical thinking. In other words, the mathematical language expressed in a virtual learning environment changes according to the communicative space available or used. In a chat, for example, mathematical language needs to be adapted to the native language; however, the oral interaction - which occurs in videoconferences - is similar to the usual communication in a face-to-face classroom. Thus, assuming that communication is part of the nature of the process of teaching and learning, it is understood that these different ways of communicating mathematical ideas transform the production of knowledge. (Souto \& Borba, 2013, p. 42)

The notion of humans-with-media emphasizes that the production of knowledge is collective and includes humans and non-human actors. As mentioned above, activity theory (Tikhomirov, 1981) inspired this notion. Souto and Borba (2016) contribute to the third generation of activity theory by showing how such a notion can give mobility to the triangles constructed by Engeström and colleagues, for example. Engeström (2006) and Leontiev (1981) emphasize that knowledge construction is social, involving rules, objectives, communities, subjects, etc. Our research, anchored on the notion of humans-with-media, shows how artifacts, one of the "vertices" of the triangles, can "collapse" and become a community or subject. Artifacts can be subject as well as community, for they are seen as part of a collective. Souto and Borba (2016) show the Internet as an actor in one instance and community in another. Technology and humans have agency. Additionally, they show it being a tool that is not outside humans, but rather one that permeates and dynamically transforms this collective.

In this paper, we use a very basic idea present in the literature that includes, among others, the notion of humans-with-media. This idea of an intershaping relationship (Borba \& Villarreal, 2005) illustrates, in short, that media shape the way humans think and, conversely, the way humans think shapes media.

The idea around this notion emphasizes that knowledge changes as different media play various roles in a collective of humans-with-media. Consistent with this idea, we use 
qualitative methods to understand the role of media in transforming knowledge and the way we comprehend it.

\section{Method}

The research studies that served as sources of data for this article were carried out between the years of 2013 and 2016. These studies aimed to investigate the role of digital technologies in the Pre-Service Mathematics Teacher Brazilian Open University courses, more specifically in the areas of Linear Algebra (Chiari, 2015) and Calculus (Almeida, 2016).

Since 2003, the Informatics, other media and mathematics education research group (GPIMEM) has been investigating pre-service and in-service mathematics teachers' distance education. For the most part, this group adopts qualitative research as a methodological approach. Doing research in distance education also raises new questions about qualitative research methodology in this virtual context, as the use of

[...] multi-logues calls for different analysis and reporting procedures. The use of different fonts and different styles of letters becomes essential in order for most readers to follow the researchers' analyses, since the linear sequence of talk, as appears in the program that records the chat room conversations, doesn't allow one to make sense of what is being discussed most of the time. (Borba \& Villarreal, 2005, p. 184)

These aspects are consistent with the notion of grounded theory (Glaser \& Strauss, 1967), the production and data analysis technique used in this paper. The technique prescribes that the theory results from data rather than preceding them and these data are a necessary consequence of the naturalistic paradigm that posits multiple realities and makes transferability dependent on local contextual factors (Lincoln \& Guba, 1985). According to Glaser and Strauss (1967), to meet these requirements, the theory must fit the situation being researched and work when put into use. By "fit," they mean that the categories must be readily (not forcibly) applicable to, and indicated by, the data under study; by "work," they mean that categories must be meaningfully relevant to and capable of explaining the behavior under study.

Grounded theory is based on the coding process in the production and analysis of the data. In open coding, the researcher constructs the categories. In axial coding, these categories are systematically developed in terms of their properties and dimensions. Finally, selective coding integrates and refines these categories into one central category, which integrates the others.

The studies portrayed in this article used methodological procedures proper to these coding processes: among them, microanalysis and constant comparisons. These techniques are rich in subjectivity and therefore difficult to describe. However, in Table 1, we describe how this procedure is performed in the construction of the categories.

In Table 1, we have the answer given by a tutor and student in one of the courses analyzed for the following question: when a student asks a question in the forums, what is the behavior of the teacher, the tutor, and other students faced with this question?

In the right-hand column, we highlight one of the codes to which we assign the answers. This process occurred in each analysis of the interviews conducted during the research for this article. The interviews were conducted with teachers, tutors, and students of the courses analyzed between the years 2015 and 2016.

In addition to interviewing various teachers, tutors, and students of the courses analyzed, direct observations were also made of the virtual learning environments in these courses. In 
Table 1 Creating codes for the data

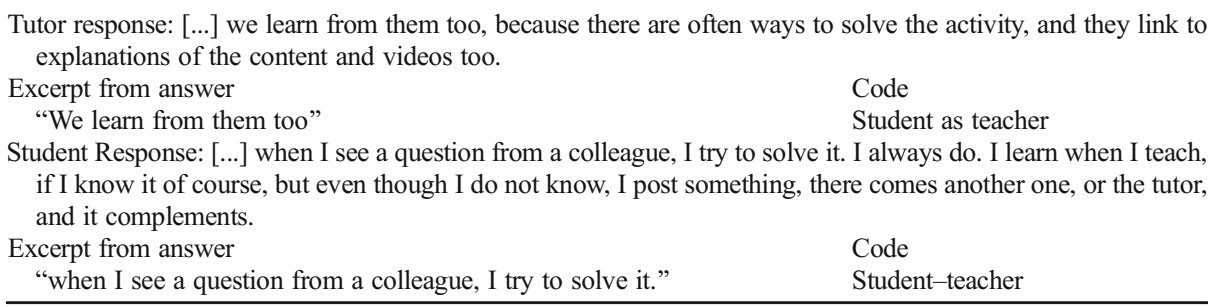

section 4, we indicate how these observations and interviews helped us in the search for the answer to our research question.

This use of different procedures for producing data is understood by Goldenberg (2011) as triangulation. According to Lincoln and Guba (1985), triangulation is a technique used to improve the interpretation of data, thus leading to greater credibility when data are analyzed.

Qualitative research, specifically grounded theory, is an appropriate methodological approach that addresses the problem we are studying. Furthermore, we believe that mathematics education, the Internet, and its interfaces can enable new practices; these practices need to be investigated, and qualitative research is the best way to explore such data. In this paper, we show how technologies, created as a "place" where online courses happen, have also become agents in the process of producing knowledge in virtual classrooms.

\section{Results and discussion}

\subsection{Interactive didactic digital material}

Investigating the role of technology in pedagogical spaces has been part of the interest of our research group for over 20 years. With the "reappearance" of distance education in the form of online education, members of our group focused their research on this type of education, yet with a different focus, including the following: subject of the curriculum, students' practice, teacher or manager's practice, or the political-pedagogical project of the Pre-Service Mathematics Teacher online distance education courses.

One of the researchers of our research group looked at the role of digital technologies in the educational processes associated with Linear Algebra in the Pre-Service Mathematics Teacher Brazilian Open University courses. There were only incremental findings specifically related to Linear Algebra in the context of their VLEs (Chiari, 2015), but we could identify new forms of textbooks or new forms of interaction that were labeled interactive didactic digital material (IDDM).

To understand the construction of IDDM and the role of digital media in it, we must first discuss two aspects related to the participation of digital technologies in the course: the range of ways to discuss themes about Linear Algebra (in a first category) and the contribution of newly produced digital educational materials (in a second category). Based on grounded theory (Glaser \& Strauss, 1967), some properties were identified in each of these categories.

In the first category, synthesized in Fig. 1, three types of themes emerged related to communication in the linear algebra classroom, which we analyzed as being the first property of this category. These three types of themes were identified as algebraic (themes with a focus 


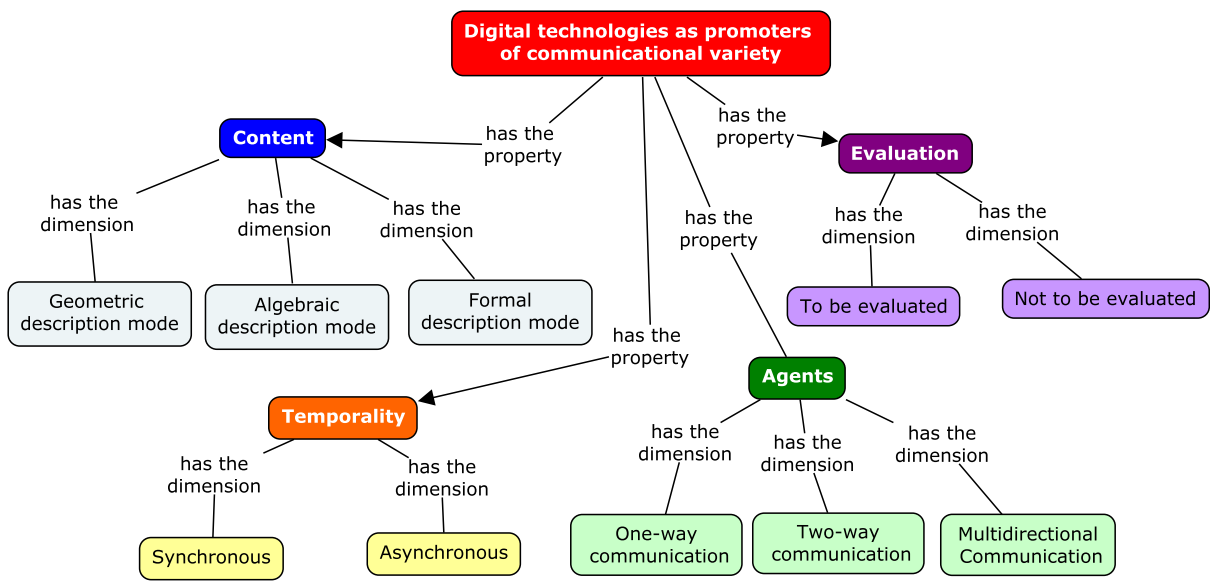

Fig. 1 Synthesis of the first category

on discussion about algebraic elements, such as matrices and determinants), formal (themes with a focus on vector spaces and sub-spaces, linear combinations, basis and dimension, etc.), and geometric modes of representation (themes with a focus on graphic representation, vectors in the Cartesian plane, etc.).

We noticed that different types of themes were associated with different digital technologies. For instance, algebraic and geometric modes could be associated with photography, as shown in Fig. 2; this resource was more commonly used when students and teachers wanted to communicate ideas related to notions like matrices or the sum of two-dimensional vectors in the Cartesian plane, for example.

The actors involved in the communication process were also analyzed as contributors to the emergence of a second property within the first category, which is of main interest for this article. However, initially, we identified features we had noticed from the beginning of our research in this area (Engelbrecht \& Harding, 2005). For example, we found that one-way, two-way, and multi-way communications represent varieties of communication in relation to the actors involved in this process (in other words, whether there were one, two, or more than two people involved).

In the tradition of our research group, we focused on the role of forums and how they shape and transform mathematical communication in the VLEs. Consequently, we also observed the influence of technology in establishing communication networks. For example, in forums and web conferences, multi-directional communication frequently occurred. However, in web conferencing, the technology resources available to students, or the lack of these resources, shaped the way students were able to express themselves mathematically, because there, they had no opportunity to share audio and video, but could only write in a chat that did not support mathematics symbols.

Two other properties were analyzed in this first category: temporality (with synchronous and asynchronous dimensions) and evaluation (with the dimensions "being evaluated" or "not rated"). In one institution we analyzed, the communication process, which involved student participation in certain forums, was evaluated, as was students' use of digital technologies.

The second category analyzed, synthesized in Fig. 3, was related to the production of digital educational materials. Three properties were established: content (with the same dimensions of the property content already presented in this text); nature of the material (with text mode, 


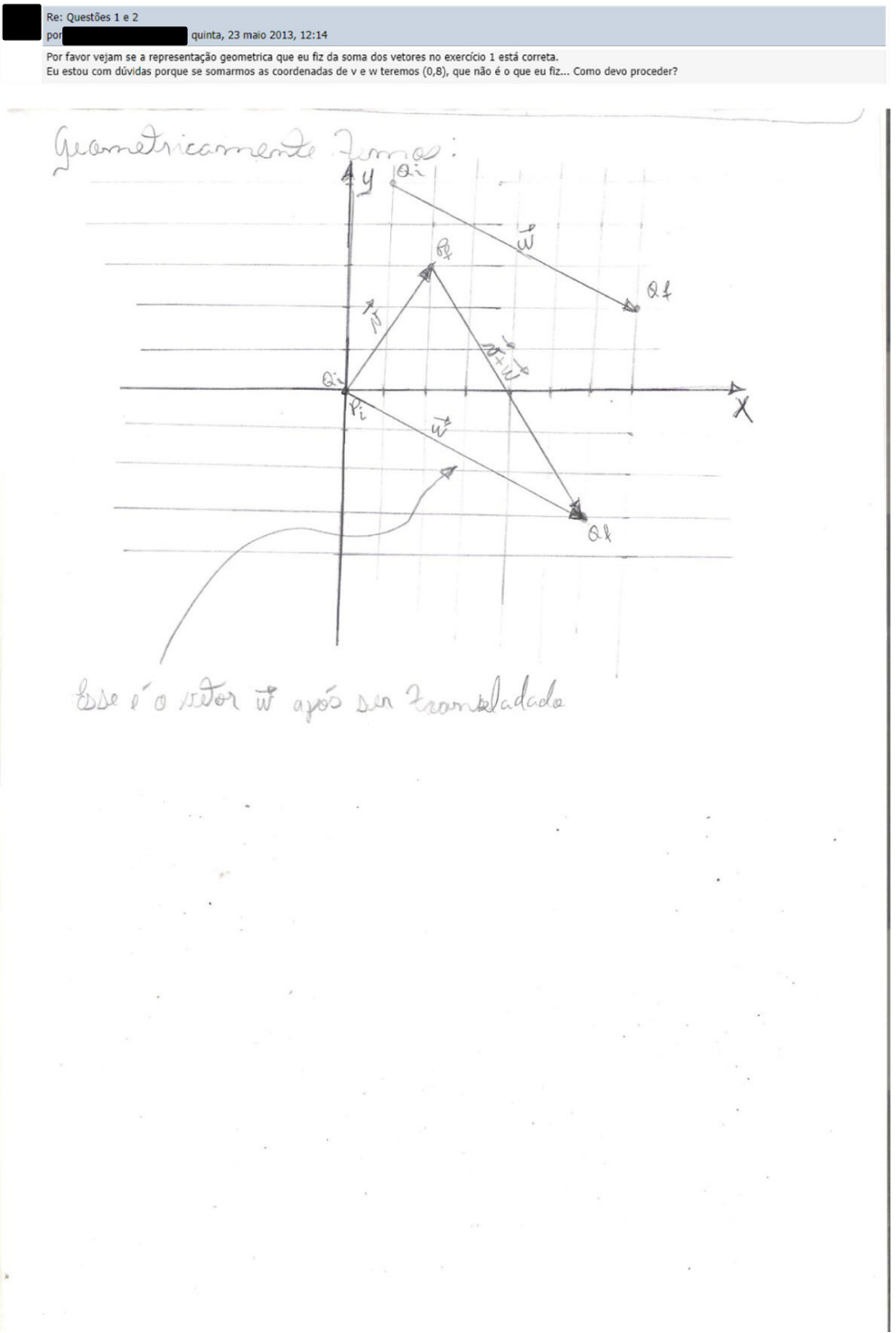

Fig. 2 Photography being used to communicate an idea associated to the geometric modes of representation

video, and multimodality); and resources involved (especially those with the participation of different resources, such as computers and software, camcorder, digital whiteboard, blackboard, and digitizing table). Content, the first property, was also seen in the first category presented, but there, it was associated with the communication process, thus showing the first relationship between the two themes that emerged from the analyses.

From the two already discussed issues, the notion of IDDM was developed to describe the transformation of communication automatically recorded by the VLE into digital learning materials used by students. The term "interactive" was added to emphasize that this material is 


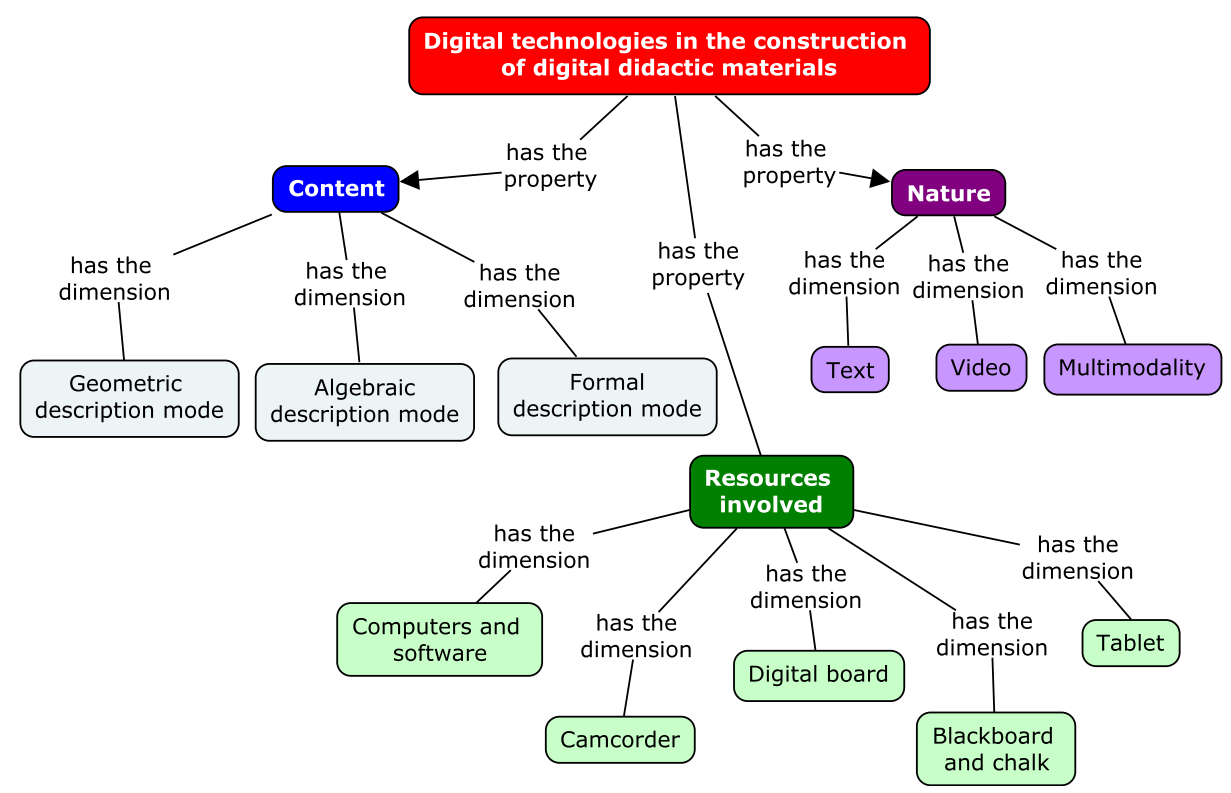

Fig. 3 Synthesis of the second category

the result and is made of interaction between the actors of the course. It should also be emphasized that it can be seen as a dynamic textbook.

We identified that although there were many study materials available, students often resorted to studying from recorded interactions in forums, especially when teachers and tutors answered questions from other students during those forums.

It is hard to imagine that something similar may happen in face-to-face contexts, with blackboards, PowerPoint presentations, and notebooks. Regular orality is the main technology of intelligence used in face-to-face classroom, and it does not register the interaction in a way that can be accessed, for instance, by a student who is not paying attention or one who has left the classroom for a short period of time. In a forum of an online course, the Internet and the VLE are not used merely as a file repository; their use explores very specific characteristics of it. The forum becomes active and has agency as student interaction is recorded and can then be retrieved. We feel this use is always possible because the "actor" forum is part of the collective of humans-with-media that produces knowledge at that moment.

Borba and Villarreal (2005) discuss the intershaping relationship, how humans and media mutually shape one another. Media have shaped students, for they need to write mathematics in a particular way in order to express themselves, which is different from the traditional classroom in cases where they have/do not have the possibility to share their audio and video. Conversely, the media used and the automatic registration of the VLE have shaped the way students have had their questions answered, since the automatic registration offers this option, and no extra intervention is needed to answer a question if it had been previously answered. This is not possible in the context of a "face-to-face orality," but it is in the VLE context. Absent students at any given moment during the forum debate could profit from the "interactive textbook under construction." Thus, it is also possible to combine the concept of IDDM with the concept of an intershaping relationship. 
The IDDM is a construction fueled by interaction. Consequently, it is found in the modes of description incorporated into the development of the discipline within each institution. In addition, it has the content that the students demand. However, it was also observed that such communication is conditional on other materials available to students. For example, in the adopted books and video lessons, the geometric description was not often explored, and the same was observed with communication during the development of the discipline.

Therefore, the IDDM produced in each VLE "is unique to each class of the discipline, changing from one class to another, even if the resources used and the tutors and teachers are the same" (Chiari, 2015, p. 178). Thus, although we emphasize the role of technology in this paper, the role of humans is also paramount in knowledge construction. In each group, there are other students who may have questions and comments inserted into the forums and the web conferencing. The students' questions are therefore "fundamental to the construction of this material, because that way, we have a material constructed from the needs of students and not from a prior planning of the teacher or tutor who may not contemplate it" (Chiari, 2015, p. 178).

In summary, IDDM is composed of interactions carried out with an initial objective, but when automatically registered in the VLE is used for purposes other than the initial purpose. More specifically, this concept articulates the communicative processes that occur in Pre-Service Teacher Mathematics courses and the available digital educational materials. This study shows, among other aspects, how the notion of IDDM constitutes itself and the interpretation of this idea as an example of intershaping relationship in which the media shape and are shaped by humans.

\subsection{Poly-teaching media}

In order to begin this section, it must be clear to the reader what we understand as teaching in online distance education. We can start by asking: who teaches in this modality? Mill (2010) creates a new word to answer this question. He understands that teaching in distance education is highly fragmented, and components of the activities that make up the virtual teaching team are assigned to various workers or groups, a design he calls poly-teaching.

According to Mill (2010), this group of workers (teachers) responsible for the educational process in distance education must be described and investigated. Moreover, he believes that the use of the term poly-teacher can avoid an interpretation that consigns the "professional" teacher solely to his or her common practice, which is the classroom teaching. We understand that the distribution of teaching in the introductory training courses for teachers in distance education, especially in the Pre-Service Teacher Mathematics courses from the Brazilian Open University, approaches the ideas presented by Mill (2010) with regard to a poly-teaching team. Thus, we think it is appropriate to adopt such a term.

As stated by Mill (2010), the poly-teaching team in distance education is formed by the following: (a) the content teacher, responsible for the preparation of the course content and the methodological adaptation of content to the profile of the course; (b) the virtual tutor, responsible in general for managing the content of the subject, and thus, the experts in the fields in which they operate; (c) the everyday teacher, responsible for directly following the students of the discipline within the virtual learning environment and managing and directing the team of tutors and students regarding the development of the content of the subject; (d) instructional designers, responsible for the design of the discipline, organization of content, and the proposed activities map. They act on the advice of the content teacher, playing an extremely important role in this collective of teachers; (e) face-to-face tutors, responsible for meeting students face-to-face in a supporting role, helping them with specific difficulties; (f) 
the multi-disciplinary team, composed of printed, audiovisual, virtual, and digital media experts; and (g) the coordinating team, responsible for the interrelations among the other members that make up the poly-teaching team.

Corroborating Mill's (2010) statement that teaching in distance education is fragmented, we understand that other "subjects" can play the role of a poly-teacher, mainly through their use of digital technologies. An example is shown by Almeida (2016), for according to him, in courses where collaborative interactions are regularly encouraged by teachers and tutors, some students may act as poly-teachers within the virtual learning environment by playing roles similar to those of the content teachers, instructional designers, virtual tutors, and everyday teachers.

As previously discussed, we see the production of knowledge as a result of a collective of humans-with-media. We also feel that such a perspective may enrich Mill's position about collective teaching and understand that the media themselves can behave like poly-teachers. To illustrate these aspects, we present some situations below. Due to the subjectivity of the procedures in the grounded theory, we have chosen excerpts from interviews and some images that synthesize our ideas. Consider the following example shown in Fig. 4:

Used in one of the courses investigated, the image depicts a video lesson about derivation. Videos of this nature, or those shared on YouTube by the students themselves, become great allies in distance learning by addressing, for example, the lack of a physical teacher. The importance of using videos is highlighted by one of the tutors studied.

[...] to study in a distance education program is sometimes a shock for students, as they feel the physical absence of a teacher; then the video plays that role a bit. The calculus class has videos; all the classes have them. I think it helps a lot; it is a differential. (Tutor)

The featured image, as well as the tutor's speech, emphasizes the importance of using videos if no teacher is physically present in the classroom. Although we are increasingly becoming accustomed to the use of technologies in everyday life, in the classroom, it is still evolving. That is, according to these data, the videos play a role of everyday teacher trainer for distance learning students. This "teacher" is always at hand.

Videos are also important in distance learning, not only due to the absence of the physical teacher, but also because they allow students to be in contact with the class model they might bring from regular classroom, in which the teacher presents the content to students in a unidirectional way. Moreover, this medium also provides support when students want to initiate approaches other than those from their teachers and tutors. In addition, it is a place where students can seek high school content they feel they need to revise.
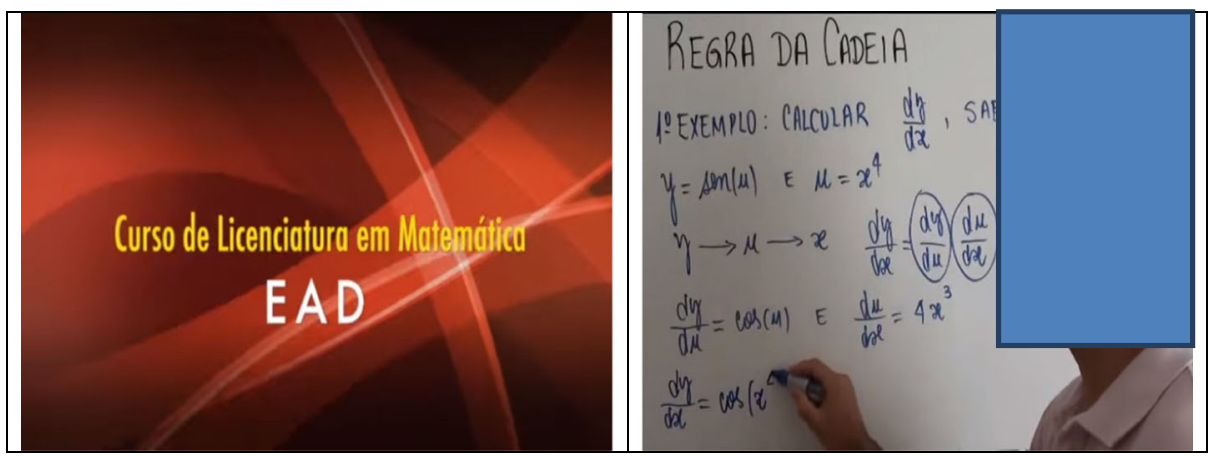

Fig. 4 Video lesson about derivation (chain rule) 
For that matter, while being an undergrad in a distance education, certain revisions from research have been made to complement the power of books [of high school] [...] The discipline's teacher made available a series of videos already produced by the university. So that is there, but that collection is more focused on the calculus of the content itself. So if at some point we need to review, we refer to YouTube videos. (Student)

When students were the learning derivatives of real functions while using the formal definition of derivatives, they reported difficulties in interpreting the concept:

These difficulties partially contributed to the exploration of whether and how similar critical transitions such as understanding the 'vanishing' increment through the concept of limit and developing a rigorous definition for the derivative as a function are discussed in today's calculus classrooms and what kind of visual mediators are involved in such discussions. (Park, 2015, p. 235)

Although the courses already contain pre-recorded video lessons produced by teachers, available via YouTube links, students also add other videos to their VLEs, because they believe these are helpful in teaching the content they need.

Another noticeable fact is the way these media are being used within the VLE to allow these environments to be transformed into venues of support for students in times of greater difficulty with the subject, as in the case of IDDM.

[...] of course we have the textbooks, have the handouts of the course, but the forum is all we really need [...] it is full of information, solved exercises, videos, links to help with solutions. (Student)

So the students do not comment explicitly, formally, but we realize that they use the forum as a source of information [...] the calculus forum is very rich, there's a lot there $[\ldots]$ the participation is very good [...] I do believe that there students have everything they need, even if sometimes they go on the Internet for content review, especially to YouTube videos. (Teacher)

This excerpt supports the idea of the influence of media and student in the design of the teaching environments as pointed out by authors, such as Lagrange and Kynigos (2014). This fact corroborates the idea of Almeida (2016) about the student acting in the role of teacher from his or her contact with different media, but also from these media acting as poly-teachers by their ability to influence the students.

Another digital technology that we consider also playing a role in the collective polyteacher is the mathematical software Geogebra and Winplot. This served as support in algebraic discussions when forums did not provide students with a complete understanding.

[...] once we organized students into two groups in the forum, one group worked with the question of the concept of limit, using software [GeoGebra] and in the other group the aim was to understand the concept of derivatives. So we introduced some situations where students had to use the software to show they were able to understand, understand the algebraic concept. (Teacher)

These technologies are identified by teachers and tutors as something that students could use together, even though it might be difficult to work with them in VLEs. The possibility of feedback software, which features a graphic or automatically calculates a derivative, can assist so that the student has insight into the content being studied. In this sense, the software itself- 
through student use - plays a role that is often considered unique to the teacher, or, in the case of the distance modality, to the poly-teacher, as described by Mill (2010). As one student indicates, software played an important role in a distance course:

[...] let me say, it [the software] taught me; I think I learned using it. For example, I saw in the handout what the teacher had said, but I only understood what a tangent line equation and derivative were when I used the applet that a friend had put there. (Student)

So, we understand that a collective humans-with-software, especially GeoGebra, can also play the formative role of teacher for these students. We understand this through our perception that such software provides for learning of the studied contents. This is certainly the case in the way it is used - as a kind of dialogue between humans and the media — producing knowledge, as poly-teachers must do when defined by Mill (2010).

We presented excerpts from the data collected by the team in several virtual classrooms of a larger project. The authors of these papers were then responsible for data collection in the Linear Algebra class and the Calculus class from different parts of Brazil. The two examples presented show how an intershaping relationship forms in a collective that involves students, teachers, and different media.

\section{Conclusion}

This paper began with the phrase "technologies have changed humankind." However, the main point of this paper is that this sentence can also be understood conversely: humans are changing technology, which is consistent with the notion of intershaping relationships (Borba \& Villarreal, 2005). One may notice that we are not referring to the issue of updating and generating new technology, as is the case of software, which offers new updates nearly daily, due to the actions of humans and available technology. We assert that humans take ownership of the different media, and students, tutors, and teachers begin to use them in ways for which they were at first neither intended nor designed. The notion of humans-with-media is dynamic in the sense that there is a constantly intershaping relationship within a given collective; a few of these relationships are documented in the qualitative studies synthetized in this paper.

The discussion around the notion of humans-with-media, intershaping relationships and a stronger connection to the third generation of activity theory has provided a framework that emphasizes the role of technology in knowledge production. To anthropomorphize technology helps to build a closer connection between humans and technology, in contrast to the traditional disjunction between them (Borba \& Villarreal, 2005). If we analyze overview papers in the field, such as those present in the journal special issue organized by Borba and Llinares (2012) and the recent ICME survey (Borba et al., 2016), one may see a diversity of theoretical perspectives and results. This paper adds to the vast number of theories on the theme, as it points out specifically how tools change knowledge production in online courses.

The theoretical human-with-media perspective helps to explain this phenomenon in the online context from the premise of considering the collective formed by humans and media as a minimum unit of analysis which may be oral or written, but that fundamentally, in the work of Borba and Villarreal (2005), is digital and computer media. In such a perspective, 
technology and humans have agency. They act and interact to produce knowledge. Moreover, as argued, technology not only changes cognition, but it also changes humans ontologically (Borba, 2012): the very notion of what "being human" means has changed with the advance of digital technology. Mobility and online education are a salient part of this when it comes to education. The reorganization of thinking, a notion that comes from the first generation of activity theory, is now connected to the different roles digital technology plays in the various components of the third generation of activity theory. The notion of humans-with-media and the work around it propose that technology is not only an "artifact," but it also plays the role of "subjects" and "community" and changes the "rules" and the "division of labor" (Souto \& Borba, 2016). In this sense, the VLE also becomes an actor and changes the rules about a student's active participation in learning.

To build an IDDM, for example, students, tutors, and teachers of a course collaboratively produce material that uniquely includes what the group demands. In addition, it is built not only for them, but also by them. In other words, for a student or a teacher, being involved in a IDDM means to have one's collaboration during interaction used as a source of study, which is made possible by the automatic registration of the VLE. Such a construction also indicates a student's contributing role, which several authors from the field of education widely recommend, since an IDDM is constructed with active student participation. In addition, it is important to mention that

[...] it is the students themselves who can acquire operational knowledge to enjoy the interactive possibilities of new technologies. The impact of new technologies is broadly reflected in the nature of what science is and what is known as socially valid knowledge. It requires deep reflection on the school and the education it offers, in the form of assessment of learning, and the teaching process itself in action.

These changes in the structures and logic of knowledge are characterized as challenges to educational institutions of all levels and especially require new concepts for the discipline approaches, new methodologies and new approaches to the teaching. (Kenski, 2008, p. 75)

It is important to use new methodologies and new approaches to teaching in the face of changes and challenges in a digital society. We argue that the idea of an IDDM can be understood as an interactive possibility for this. We also believe that the occurrence of an IDDM can be natural and unintentional, even though it can (and should) be initiated by the teacher. But initiating is just one part of the didactical activity; the didactical responsibility should be shared by students as well (Chiari, 2015). Situations such as these allow the student to have agency in the educational process, similar to what Almeida (2016) states: teachers of online distance courses can themselves become apprentices. In the Freirean fashion, students can become teachers, and teachers can learn by the way students interact with one another. The agency of digital technology, in this case, the forum, can help with this. The agency of digital technology is, of course, a result of human work that by intention is "stocked," which is the way the forum here was designed. The forum was not intended to be a teaching tool, but, as we argued, it became one in this collective of humans-with-forum. Students built upon the interactions of this "interactive textbook," adding new layers of meaning to interactions that had already occurred.

In the case of poly-teaching media, we have shown evidence that software and videos were also part of the distributed teaching, teaching which is shared among human and non-human actors. Teaching in online mathematics education is distributed among 
several human actors, virtual context, and the technology used. Sometimes a video class may play the role of a traditional teacher - a content transmitter - and in another, it may play the role of a teacher who believes in interaction; in this case, students keep the interaction "naturally frozen" in a forum, which may then be explored by others online. Technologies shape humans, and humans also shape technology in ways other than those designers had originally intended.

Although we have related the notions of IDDM and poly-teaching media to learning and teaching, respectively, we do not actually want such a separation. In fact, we believe that video and software impact learning in distance education courses and additionally, we consider IDDMs as being poly-teacher media.

But for all of this to make sense, we believe we need to break from the idea of the teacher as the center of any discussion and allow for the idea that the interactions that may occur within the VLE are closer to what Kazak, Wegerif, and Fujita (2015) mean by dialogue, that is, participants of courses interacting collaboratively.

In a dialogue, the other that is addressed is located outside of the self but also appears as a voice on the inside of the self-shaping utterances from within. Bakhtin (1981) distinguishes between the 'persuasive' voice that enters inside my words and changes them from within and contrasts this to the authoritative voice that remains outside and can be either acquiesced to or resisted but cannot be engaged in dialogue. (Kazak et al., 2015, p. 107)

We believe that education should be an essential dialogical process that requires deep listening and conscious intention. Thus, there must be a dialogical relationship of deep listening, a relationship that becomes even more important in online distance education, where the role of a teacher is "distributed" among different human beings and digital technologies, in other words, among poly-teachers-with-media. As a result, we may have new kinds of "textbooks" like the IDDM, where course content is dynamically shaped by technologies, students, and poly-teachers.

We understand that in a mathematics classroom of an online distance course, it is necessary to create conditions to allow for the transmitting of information as well as for the construction of knowledge. This construction of knowledge is acquired not only by access to information, but also by the interaction that occurs among students, tutors, and teachers. Thus, for the IDDM and the poly-teaching media to emerge in distance courses, it is necessary that interactions occur collaboratively among participants. This, once again, corroborates the idea that "the theoretical orientation of each team, a characteristic of the academic settings, influences design principally at the level of the educational aims" (Lagrange \& Kynigos, 2014, p. 400).

Thus, it is necessary to make the reader aware of the importance of the context of the research, the reconfiguration of virtual learning environments, and the appropriation of the media by the participants of the courses so that we have an understanding of IDDM and polyteaching media.

Based on what has been argued, one can see that interaction plays a key role in distance education. This interaction becomes necessary because the exchange of experiences and the exposure to reasoning are actions that constitute the "doing" of mathematics. Consistent with this need are the concepts presented in this article, those of IDDM and poly-teacher, as they promote dialogue, bring students to play an active role in their learning, and highlight new roles for digital technologies. 


\section{References}

Almeida, H. R. F. L. (2015). Das Tecnologias às Tecnologias Digitais e seu uso na Educação Matemática [From technologies to digital technologies and their use in mathematics education]. Nuances: Estudos Sobre Educação, 26(2), 222-239.

Almeida, H. R. F. L. (2016). Polidocentes-com-Mídias e o Ensino do Cálculo I [Poly-teacher-media and the teaching of Calculus I] (Doctoral dissertation). Universidade Estadual Paulista "Júlio de Mesquita Filho," Rio Claro.

Bairral, M. A. (2005). Desenvolvendo-se criticamente em matemática: a formação continuada em ambientes virtualizados [Developing critically in mathematics: continuing education in virtualized environments]. In D. Fiorentini \& A. M. Nacarato (Eds.), Cultura, formação e desenvolvimento profissional de professores que ensinam Matemática: investigando e teorizando a partir da prática [Culture, teacher training, and professional development of teachers who teach mathematics: investigating and theorizing from practice] (pp. 49-67). Musa Editora: São Paulo.

Bakhtin, M. M. (1981). The dialogic imagination: Four essays by M.M. Bakhtin (C. Emerson \& M. Holquist, Trans.). Austin, TX: University of Texas Press.

Borba, M. C. (2009). Potential scenarios for Internet use in the mathematics classroom. ZDM Mathematics Education, 41, 453-465.

Borba, M. C. (2012). Humans-with-media and continuing education for mathematics teachers in online environments. ZDM, 44, 802-814.

Borba, M. C., Askar, P., Engelbrecht, J., Gadanidis, G., Llinares, S., \& Aguilar, M. S. (2016). Blended learning, e-learning and mobile learning in mathematics education. ZDM-The International Journal on Mathematics Education, 48, 589-610.

Borba, M. C., Gracias, T. A., \& Chiari, A. S. S. (2015). Retratos da pesquisa em Educação Matemática online no GPIMEM: um diálogo assíncrono com quinze anos de intervalo [Pictures of online Mathematics Education research in GPIMEM: an asynchronous dialogue with a fifteen year interval]. Educação Matemática Pesquisa, 17(5), 843-869.

Borba, M. C., \& Llinares, S. (2012). Online mathematics teacher education: overview of an emergent field of research. $Z D M, 44,697-704$.

Borba, M. C., \& Villarreal, M. E. (2005). Humans-with-media and the reorganization of mathematical thinking: information and communication technologies, modeling, experimentation and visualization (Vol. 39). New York: Springer.

Chiari, A. S. S. (2015). O papel das tecnologias digitais em disciplinas de Álgebra Linear a distância: possibilidades, limites e desafios [The role of digital technologies in distance linear Algebra disciplines: possibilities, limits, and challenges] (Doctoral dissertation). Universidade Estadual Paulista "Júlio de Mesquita Filho," Rio Claro.

Clay, E., Silverman, J., \& Fischer, D. J. (2012). Unpacking online asynchronous collaboration in mathematics teacher education. ZDM, 44(6), 761-773. https://doi.org/10.1007/s11858-012-0428-8

Engelbrecht, J., \& Harding, A. (2005). Teaching undergraduate mathematics on the Internet. Educational Studies in Mathematics, 58, 235-276.

Engeström, Y. (2006). Activity Theory and expansive design. In S. Bagnara \& G. C. Smith (Eds.), Theories and practice of interaction design (pp. 3-24). Mahwah, New Jersey: Lawrence Erlbaum.

Glaser, B. G., \& Strauss, A. (1967). The discovery of grounded theory: Strategies for qualitative research. London: Weidenfeld and Nicolson.

Goldenberg, M. (2011). A arte de pesquisar: como fazer pesquisa qualitativa em Ciências Sociais [The art of research: how to do qualitative research in Social Sciences] (12th ed.). Rio de Janeiro: Record.

Goos, M., \& Geiger, V. (2012). Connecting social perspectives on mathematics teacher education in online environments. ZDM-The International Journal on Mathematics Education, 44(6), 705-715.

Gueudet, G., Sacristán, A. I., Soury-Lavergne, S., \& Trouche, L. (2012). Online paths in mathematics teacher training: New resources and new skills for teacher educators. ZDM, 44(6), 717-731. https://doi.org/10.1007 /s11858-012-0424-Z

Hoyles, C., \& Noss, R. (2003). What can digital technologies take from and bring to research in mathematics education? In A. J. Bishop, M. A. Clements, C. Keitel, J. Kilpatrick, \& F. K. S. Leung (Eds.), Second international handbook of mathematics education (Vol. 10, p. 323-349). Dordrecht: Kluwer Academic Publishers.

Jacinto, H., \& Carreira, S. (2017). Mathematical Problem Solving with Technology: the Techno-Mathematical Fluency of a Student-with-GeoGebra. International Journal of Science and Mathematics Education, 15(6), 1115-1136. https://doi.org/10.1007/s10763-016-9728-8

Kazak, S., Wegerif, R., \& Fujita, T. (2015). The importance of dialogic processes to conceptual development in mathematics. Educational Studes in Mathematics, 90(1), 105-120. 
Kenski, V. M. (2008). Tecnologias e ensino presencial e a distância [Technologies and face-to-face \& online distance teaching] (6th ed). Campinas: Papirus.

Kynigos, C., \& Kalogeria, E. (2012). Boundary crossing through in-service online mathematics teacher education: The case of scenarios and half-baked microworlds. ZDM-The International Journal on Mathematics Education, 44, 733-745. https://doi.org/10.1007/s11858-012-0455-5

Lagrange, J.-B., \& Kynigos, C. (2014). Digital technologies to teach and learn mathematics: Context and recontextualization. Educational Studes in Mathematics, 85(3), 381-403.

Leontiev, A. N. (1981). The problem of activity in psychology. In J. V. Wertsch (Ed.), The concept of activity in soviet psychology. New York: M. E. Sharpe. Inc..

Lévy, P. (1993). As tecnologias da inteligência: o futuro do pensamento na era da informática [The technologies of intelligence: the future of thinking in the computer age] (p. 34). Rio de Janeiro: Editora.

Lincoln, Y. S., \& Guba, E. G. (1985). Naturalistic inquiry. London: Sage Publications.

Maltempi, M. V., \& Malheiros, A. P. S. (2010). Online distance mathematics education in Brazil: Research, practice and police. ZDM Mathematics Education, 42, 291-303.

Mill, D. (2010). Sobre o conceito de Polidocência ou sobre a natureza do processo de Trabalho Pedagógico na Educação a Distância [On the concept of the polyteacher or on the nature of the process of pedagogical work in distance education]. In D. Mill, L. R. C. Ribeiro, \& M. R. G. Oliveira (Eds.), Polidocência na Educação a Distância: múltiplos enfoques [The distance learning polyteacher: multiple approaches] (pp. 23-40). São Carlos: EdUFSCar.

Park, J. (2015). Is the derivative a function? If so, how do we teach it? Educational Studies in Mathematics, $89(2), 233-250$.

Rabardel, P., \& Waern, Y. (2003). From artefact to instrument. Interacting with Computers, 15(Linkojing), 641645.

Silva, M. (2000). Sala de aula interativa [The interactive classroom]. Rio de Janeiro: Quartet.

Souto, D. L. P., \& Borba, M. C. (2016). Seres Humanos-com-Internet ou Internet-com-Seres Humanos: uma troca de papéis? [Humans-with-Internet or Internet-with-humans: an exchange of roles?]. Revista Latinoamericana de Investigación En Matemática Educativa, 19(2), 217-242. https://doi.org/10.12802 /relime.13.1924

Souto, D. L. P., \& Borba, M. C. (2013). Transformações Expansivas em Sistemas de Atividade: o caso da Produção Matemática com a Internet [Expansive transformations in activity systems: the case of Mathematical Production using the Internet]. Perspectivas Da Educação Matemática, 6, 70-89.

Tikhomirov, O. K. (1981). The psychological consequences of computerization. In J. V. Wertsch (Ed.), The concept of activity in soviet psychology (pp. 256-278). New York: M. E. Sharpe. Inc.

Zabel, M., \& Almeida, H. R. F. L. (2015). Um retrato da formação online do professor de Matemática [A picture of online mathematics teacher training]. In M. C. Borba \& H. R. F. L. Almeida (Eds.), As Licenciaturas em Matemática da Universidade Aberta do Brasil (UAB): uma visão a partir da utilização das Tecnologias Digitais [Mathematics teacher education of the Open University of Brazil (UAB): a view from the use of digital technologies]. Livraria da Física: São Paulo. 